Gelis Tarihi:17.10.2016

Kabul Tarihi:30.11.2016
Mediterranean Journal of Humanities

mjh.akdeniz.edu.tr

$\mathrm{VI} / 2$ (2016) 265-278

\title{
Poetry Slam: Edebiyatın Oyun Bahçesi
}

\author{
Poetry Slam: The Playground of Literature
}

Safiye GENÇ*

Öz: 1986'da ilk kez Chicago'da düzenlenen poetry slam, amatör şairlerin küçük kafe veya gece kulüplerinde sergiledikleri bir tür sahne yarışmasıdır. ABD'de hızla popüler olan bu yarışma 90'ların ortasında Almanya'da da yaygınlaşmaya başlamıştır. Öyle ki, Almanya'daki poetry slam camiası 2000'den fazla icracısı ile dünyadaki ikinci büyük genç şairler (İng. slammer) topluluğu halini almıştır. Bu çalışma, edebiyattan ve özellikle şiirden uzaklaşan yeni nesli kendisine çeken poetry slam'i ele almaktadır. Bu amaçla son yıllarda uluslararası yarışmalarda ve Almanya'da sergilenen slam'ler incelenmiştir. Özellikle ses ve sözün hangi şekillerde birleştirildiği ele alınmaktadır. Örneğin, sunumlarda konuşma hızının, uzun veya kısa duraksamaların, sesin yüksekliğinin ve alçalmasının içerik ile ne şekilde uyum sağladığı incelenmiştir. Bunun yanı sıra beden dili ve sahne unsuruna da değinilmektedir. Bu özellikler bir kapışma örneği üzerinde gösterilmeye çalışılmıştır.

Anahtar sözcü̈kler: Poetry Slam, Slam Poetry, Hiphop Kültürü, Şiir Yarışması, Sahne Performansı

Abstract: First held in Chicago in 1986, the poetry slam is a form of stage contest where amateur poets recite their poems in small cafes or nightclubs. After rapidly gaining popularity in the U.S.A., such events began to spread more widely in Germany in the mid-1990's. Indeed, the poetry slam community in Germany has become the second largest group of young poets (slammers) in the world with more than 2000 performers. This research concerns the poetry slam as a phenomenon which attracts the new generation, who appear to have been moving away from literature and from poetry in particular. In this respect, recent slam performances in international competitions and in Germany have been examined, with a special focus upon how voice and speech are combined. For instance, how variables such as speech tempo, long or short pauses, and the variation of spoken pitch (intonation) are attuned to the contents in such slam performances were all analyzed. In addition, the use of body language and stage performance is addressed. All of these elements have been illustrated through the example of slam contest.

Keywords: Poetry Slam, Slam Poetry, Hip-hop Culture, Poetry Contest, Stage Performance

\section{Giriş}

Almanya'da son yıllarda şiirin Rönesans'ı yaşanmaktadır. Bu yeniden doğuş popüler kültürün içinden gelse de, amatörler olduğu gibi usta yazar, şair, oyuncu ve müzisyenler de bu yeni şiir türünün kitlelere ulaşmasına hizmet ediyorlar. Seslendirilerek dile getirilen bu türe "Slam Poetry"

*Yrd. Doç. Dr., Akdeniz Üniversitesi, Edebiyat Fakültesi, Alman Dili ve Edebiyatı Bölümü, Antalya. safiyegenc@akdeniz.edu.tr

Söz konusu araştırma, genel hatları ile 06-07 Ekim 2016 tarihinde Antalya'da, Akdeniz Üniversitesi, Edebiyat Fakültesi, İngiliz Dili ve Edebiyatı Bölümü tarafından düzenlenen 16. Uluslararası Deyişbilim Sempozyumu'nda sözel bildiri olarak sunulmuştur. 
(Tr. Kapışma Edebiyatı) ve seslendirildiği etkinliğe "Poetry Slam" (Tr. Şair Kapışması) denmektedir.

$\mathrm{Bu}$ çalışmada önce şair kapışmasının kimler tarafından geliştirildiği ele alınacaktır. Poetry Slam ve Slam Poetry kavramları açıklanacak, özelliklerine değinilecektir. Bu özelliklere örnek olarak çalışmanın analiz kısmında Avusturyalı sanatçı Lisa Eckhart'ın bir şair kapışması performansı incelenecektir. Video kaydına dayanan bu performansın analizi, transkripsiyon üzerinden yapilacaktır.

\section{Tarihçe}

Şair Kapışması 1980'lerde Chicago'da başlamıştır. Bu yarışma formatının kurucusu kabul edilen Marc Kelly Smith, şairlerin kendi şiirlerini okudukları okuma akşamlarına katılırken bu okumaları ve mekânları ne kadar sıkıcı ve dinleyiciyi edebiyattan uzaklaştırıcı bulduğunu Baverya Televizyonu için hazırlanan bir belgeselde dile getirmektedir (Urbach 2015). Gençliğinden beri kendisi de şiir yazan, Caz ve Blues müziğinin etkisinde kalan Smith, Chicago kulüplerinde bu müzikleri dinlerken aldığ 1 tadı, şiir dinletilerinde alamadığını söyler. Bu durumu değiştirmek için 1984'ten itibaren Chicago'da bulunan Get Me High Lounge adlı Caz kulübünde okuma akşamları düzenler. Edebiyatı sahne performansı olarak canlandırmayı planlayarak şair arkadaşları ile birlikte Chicagoer Poetry Ensemble'1 kurar. Birlikte şiir yazıp sahnede canlandırırlar (Hager 2006, 7). Smith böylelikle sahne oyunculuğu sanatı ile edebiyatı birleştirmiş olduklarını düşünür (Urbach 2015).

Geç saatlere doğru kafedeki dinleyicilerin ilgisinin azaldığını fark eden Smith etkinliğe biraz daha heyecan katmak için yarışma formatını geliştirir. Smith için yarış özelliği, seyircinin ilgisini canlı tutmak için sadece bir tür "hile" konumundadır (Urbach 2015). Asıl olan daima eserdir. Her Pazar akşamı The Green Mill adlı Caz kulübünde bu amaçla edebiyat yarışmaları düzenlemeye başlar. Seyircilerin arasından da her zaman birilerinin çıkıp yarışa dâhil olma şansı vardır. Böylece günümüzde de devam eden "Uptown Poetry Slam" hayata geçirilmiş olur (Hager 2006, 7). Yerel medyanın oldukça ilgisini çeken Uptown Poetry Slam kısa sürede popüler olur. Şair kapışması bu formatı ile diğer şehirlerde de düzenlenmeye başlanır. 1989 yılında, Bob Holman, kapışma formatını New York'un tanınmış sanat kulübü Nuyorican Poets Cafe'nin Cuma akşamlarına taşıyınca diğer şehirlere de hızlı bir şekilde yayılan şair kapışması, sahnede şiir performansları ile 90'lı yılların edebiyat dünyasını canlandırır.

1990 yılında ABD'de ilk ulusal şair kapışması düzenlenir. Kapışma kaleleri olan Chicago, New York ve San Francisco'dan şairler katılır. 1994 yılında "Aloud! Noises from the Nuyorican Poet's Cafe" kapışma şiiri antolojisi yayımlanır (Algarín \& Holman). ABD'de American Book Award'1 kazanan bu kitap, tüm zamanların en çok satan şiir derlemesi olur (Hager 2006, 9).

Almanya'nın şair kapışması ile tanışması, ABD'li şairlerin Avrupa turnesine çıkıp farklı şehirlerde şair kapışması düzenlemeleri ile 90'l y yllarda başlar. Turneye çıkan bu şairlere ait "Slam! Poetry. Heftige Dichtung aus Amerika" adlı şiirlerin derlemesi 1993'de Almanya'da basılır (Beatty \& Marrs). Bir yıl sonra ikinci baskısı çıkar. 1993'te "Dichter in den Ring" (Tr. Şairler Ringe) adı altında Köln'de ilk Alman Ulusal Edebiyat Yarışması düzenlenir (Preckwitz 1997, 63). Holman'ın önerisi doğrultusunda düzenlenen bu yarışmanın amac1, birinci gelen şairin ABD "National Poetry Slam"e gönderilmesidir. Berlin, Düsseldorf, Münih ve Hamburg başı çekmek üzere şair kapışmaları düzenli olarak şehirlerin belli bar ve kafelerinde düzenlenmeye başlanır. İlk kapışmalarda orijinaline sadık kalarak İngilizce yapılan sunumlar giderek daha çok Almanca yapılır.

1997’de ilk Alman Ulusal Şair Kapışması düzenlenir. İlgi çok büyüktür. 1999'da ise bu ya- 
rışmaya İsviçre ve Avusturya da dâhil olunca yarışmanın adı "Almanca Uluslararası Şair Kapışması" (İng. German International Poetry Slam) olarak değişir (Hager 2006, 14).

\section{Şair Kapışması (Poetry Slam)}

Şair kapışması, şairlerin kendi metinlerini seslendirdiği, yarışmanın galibini seyircinin tayin ettiği, sahne performansına dayalı bir edebiyat yarışmasıdır.

Slam kelimesi İskandinav Dilleri‘nde (İsveçęe slämma, Norveççe slemma) yansımalı olarak bir kapının hızlıca çarparak kapanmasını ifade eder. Diğer bir anlamı da "sertçe eleştirmek"dir. Konuşma dilinde "aşağılamak", "yenmek" gibi anlamları da vardır (Webster's Dictionary 1963, 817). 1994 y1lında, "The Source" adlı hiphop dergisini kaynak göstererek Black American English Sözlüğü, slam kelimesi için "competitive performance" (Tr. yarlşmalı performans) tanımını getirir (Preckwitz 1997, 21). Alman Duden Sözlügü ise 2009'dan itibaren slammen kelimesini bir fiil olarak kaydetmekte (Wirag 2014, 273) ve "bir şair kapışmasında yarışmak" olarak açıklamaktadır.

Şair kapışmasında bir performans sergilenir. Bu performans, sesi kullanma, beden ve yüz hareketleri, seyirci ile göz teması ve çoğu zaman da söze ritim katma becerisine dayanır. Performans boyunca seyirci ve şair arasında bir görevdaşlık vardır. Bu enerji hem şairi hem seyirciyi beslemektedir. Sahnede şiir ve nesir, hiphop, komedi ve eğlence ile birleşir, dramatik monologlarla karışır ve bu yolla edebiyat eğlence ile bir araya gelmiş olur (Hager 2006, 4). Bu özelliği genç insanların ilgisini çekmektedir.

Tüm dünyada geçerli olan üç kuralı vardır şair kapışmasının: Şair sadece kendi eserlerini canlandırabilir; şaire belli bir süre verilir ve bu süre aşılamaz (etkinliğe göre üç ile yedi dakika aras1); sahnede kostüm veya aksesuar kullanılmasına izin verilmez. Şair kapışması, bir sunucu tarafindan yönetilir. Sunucuya Master of Ceremony, kısaca " $M C$ " denir. Bu terim hiphoptan alınmıştır. $M C$ her kapışmanın başında sahneye çıkar, seyirciye kuralları anlatır ve genellikle seyirciler arasından jüriyi seçer. Rastgele olabileceği gibi seyircilerden el kaldıranlar arasından da jüri seçimi gerçekleşebilir. Jüriye seçilenler, sunumları 1 ile 10 arası bir puanla değerlendirir. Küçük kafelerde seyirci, alkış ile kazananı belirler. Seyirci, genelde edebiyat ve felsefe ile ilgilenen öğrenciler, akademisyenler veya kültür ve sanata ilgi duyan kişilerden oluşmaktadır. Kapışanlar da yine bu seyirci kitlesi içinden çıkmaktadır. Şair kapışmaları bu nedenle, edebiyat dünyasını demokratikleşme fırsatı olarak da görülmektedir. Kapışmalarda herkes, sahneye kendisini denemek için çıkabilir ya da seyirci olarak sunulanı değerlendirebilir. Edebiyat ve şiir, kitleden uzak fildişi kulede, sadece elit bir tabaka tarafından üstlenilen bir uğraş olmaktan çıkmaktadır. Ulusal organizasyonlarda, kapışanlar, geldikleri şehirleri temsil ederler. Almanya, İsviçre ve Avusturya'da düzenli olarak her ay yaklaşık 80 şair kapışması organize edilmektedir (Anders 2007, 1). Bu işe gönül vermiş olanlar böylelikle şehirlerarası bir edebiyat paylaşımı yanı sıra bir tür iletişim ağı da kurmuş oluyorlar. Kendilerine "Slamily" (slam-family) demelerinin de sebebi bundandır (Urbach 2015).

Kapışanlar arasında öykücüler, rapçiler, şairler, komedyenler vs. vardır. Çok başarılı olmayan sunumlarda bile seyirci, sahnedeki kişiyi destekler ve alkışlar. Sözsel dil kadar söz dışı dil de (sahnede duruş, beden dili vs.) başarıyı belirler. Kapışanlar incelendiğinde üç değişik sunum tarzı göze çarpmaktadır (Nikolai, Orjuela \& Schrenk 2009, 139-141). Seyirciyle göz teması kurmadan metnini okuyan ve beden dilini, mimik ve jestleri az ya da hiç kullanmayan kapışanlar, genelde monoton bir ses tonu ile metinlerini sunarlar. Bu tarz sunumlarda metnin çok iyi olması gerekmektedir, çünkü performans ikinci planda kalır. İkinci tür kapışan, seyirci ile göz teması kurar, metnine başlamadan önce kısa bir giriş konuşması yapabilir. Performansı canlı ve duygusaldır. 
Üçüncü sunum tarzı ise ağırlıklı olarak performansa dayalıdır. Seyirci ile sunum boyunca temastadır. Seyirciye sorular yöneltir, tepkisine yorum getirir. Beden dili yoğun olarak devreye girdiği gibi ses oyunları da kullanılır ve ses tonu, metne uyum sağlayacak şekilde değişir.

Kapışan, metninde saymaca bir dünya oluştursa da kendi öznel bakış açısı ve kişisel özelliklerini seyirciye yansıtır. Bu bilinçli yapılır. Kapışan, belli bir yöresel ağızla konuşabilir ya da örneğin argo kullanabilir. Günlük hayatında nasıl giyiniyorsa sahneye de öyle çıkar. Aslında kapışan kendini oynamaktadır. Herhangi bir rolün içinde kaybolmazlar ve bireyselliklerini vurgulayarak kendileri hakkında farklı bir imge yaratmazlar (Nikolai et al. 2009, 146).

Şair kapışması, hiphop kültürünün "battle" (Tr. atışma, dövüş) karakterinden esinlenmiş ve oluşmuştur. Hiphop kültüründe atışmalar genelde karşılıklı ve yüz yüze olmasına rağmen (ör. rap atışmaları) şair kapışmasında arka arkayadır; bir sanatçı sahneden ayrıldığında diğeri gelir. Hiphop kültüründe ve şair kapışmasında "slam" kelimesi; şehir hayatı, katılımcılık, gençlik, etkinlik, eğlence, yarışma ve hız gibi kavramları çağrıştırır (Wirag 2014, 274).

\section{Kapışma Edebiyatı (Slam Poetry)}

Lirik ve epik metinler sahne sanatı ile bir araya gelseler de genellikle prozodi ve uyak dikkat çektiği için kapışma edebiyatı, tür olarak şiire dâhil edilir. Bu edebiyat, canlı olarak seyirci karşısında sunulmak üzere yazılır (Smith \& Kraynak 2004, 3). Bir diğer özelliği de sahnede canlandırılan metinlerin birbiri ile yarışıyor olmasıdır.

Tarihe bakıldığında şair atışmaları geleneğinin çok geriye gittiği görülmektedir. Örneğin, Kelt ve Cermen kültüründe hükümdarların kale ve saraylarında, saray şairleri (İng. bard (Webster's Dictionary 1963, 69); Batı Cermen Skop; Kuzey Cermen Skalden (Meyers Lexikon 1986, 52) vardır. Bu şairler telli müzik aletleri ile methiyeleri, ağıtları, kahramanlık ve savaş şiirlerini şarkı olarak okurlar. Melodi, ritim ve ses tonu yanı sıra sunumdaki performansları da önemlidir. Yine aynı şekilde uzun öykü ve hikâyeleri konu eden balatlar da şarkı olarak okunan şiirlerdir. Alman Edebiyatı'nda, Ortaçağ şairleri arasındaki atışmalar bilinmektedir. Şiirsel aktarımların ilk halleri hep sözseldir ve teatral bir şekilde dile getirilmiştir. Bu açıdan bakılırsa 80'li yıllarda ortaya çıkan kapışma edebiyatı, bu geleneğin bir nevi yeniden keşfidir.

Çağımız edebiyat tarihinde kapışma edebiyatı bazı akımlar ışığında değerlendirilebilir. Dadaizm, şiirin okunmasını ve canlı sunulmasını savunmuştur (bk. Riha \& Wende 1992, 9). 1950'li yılların başından itibaren Amerika Birleşik Devletleri'nde Beat Generation adı altında toplanan şairler de şiirlerini sahnede canlı sunmaktaydı. Bu şiirler özellikle Latin Amerikalılar ve siyahilerin toplumsal eleştirilerini dile getirdikleri canlı sunumları kapsamaktaydı. Bu anlamda, azınlık grupların kendini ifade edebileceği platformlar arasında, New York'taki Nuyorican Poets Cafe dikkat çekmektedir. "Nuyoricans" (New Yorkers-Puerto Ricans), New York'ta yaşayan Porto Rikolulara takılan ve küçümseme içeren bir hitap şekliyken (Riedel 2016, 3) Nuyorican Poetry adı altında tanınmaya başlanan canlı şiir okumalarıyla olumsuzluk ifadesi olmaktan çıkarak özel bir edebiyatın simgesi olmuştur. Beat Generation akımından etkilenen bazı Alman sanatçılar, 90'lı yıllarda Social Beat akımını başlatmışlardır. Social Beat, Almanya'da bir alt kültür ürünü olarak kalır. Beat Generation ve Social Beat akımının bir tür hiphop yorumu olan kapışma edebiyatı ise alt kültürden gelip hızla popülerliğini arttırır.

Kapışma edebiyatının en önemli özelliği sözsel oluşudur. Metin, canlı sunum için hazırlanır. Tonlama, vurgu gibi seslendirme özellikleri metne zenginlik ve ifade çeşitliliği katar. Kapışma edebiyatında metinler çoğu kez uyaklıdır. Mısra içi uyaklar olan aliterasyon ve asonans kullanımı, akıcı okunan metinlere belli bir ritim kazandırır. Ritim, hızlanma ve yavaşlama ile de kontrol edilir. Yansıma sesler çokça kullanılır. Bazen metin ortasında, birden beliren uzun süreli 
susma ya da belli noktalarda belirgin kısa susmalar, anlatılmak isteneni destekler. Dinleyicide, sözsel dil göstergelerinin dışında sözsel dile eşlik eden bu tür unsurlar da çağrışımlara sebep olur ve dinleyicinin hayal gücünü harekete geçirir.

Seyirci ile etkileşim, kapışma edebiyatının diğer bir özelliğidir. Metinler seyircinin tepkisi düşünülerek yazılır. Örneğin, seyirciye retorik sorular sorulur; performansın bazı kısımlarında seyirciden katılım beklenir. Sunum için kapışana verilen sürenin kısıtlı olması da metinler oluşturulurken dikkate alınır.

Kapışma edebiyatında genellikle güncel konular işlenir. Bazen bu güncel konular, balat, ağıt gibi klasik edebiyat türleri ile dile getirilmektedir. Bazen de bir mektup, bir günlük yazısı içinde verilir. Bu metinlerarasılık, kapışma edebiyatında sıkça görülür. Klasik ile modernin, alışılmış ile alışılmamışın, bilinen ile bilinmeyenin, yerli ile yabancının karışımı, seyirciyi şaşırtma d1şında, metinlere ve performanslara özgünlük de katmaktadır.

Konular, siyasi ve toplumsal olabildiği gibi öznel de olabilir. Başkalarının düşüncesi ya da genel bir bakış açısı sergilenmez. Çoğu şair kendi yaşadığı bir olayı ya da edindiği bir izlenimi, durumu abartarak ya da küçümseyerek dile getirir. Sunumlar, seyirciyi güldürmeye yönelik olabildiği gibi duygulandırmaya da odaklanmış olabilir. Metnin kendisi farklı bir dil gerektirmediği sürece, kullanılan dil genelde günlük dildir. Argo ve bölgesel ağızlar da kullanılır.

\section{Bir Kapışma Edebiyatı Örneği}

2015 Almanca Kapışma Yarışması Finalleri Augsburg'da yapıldı (Slam 2015). Almanya, Avusturya, Lüksemburg ve İsviçre elemelerinden gelen dokuz finalistin yer aldığı yarışmanın birincisi Almanya'dan Jan Philipp Zymny seçildi. Jüri, seyirciler arasından belirlendi. Kapışanlara beş dakika sahne süresi verildi. Küçük bir puan farkı ile yarışmada ikinci olan Avusturyalı Lisa Eckhart'ın final sunumu bu çalışmada kapışma edebiyatı örneği olarak incelenecektir. Kapışma, video kaydı kullanılarak EXMARaLDA 1.4.3 Transkripsiyon Editörü ile gerçekleştirilmiştir. Transkripsiyonda genel ölçüde HIAT-Transkripsiyon Kuralları (Rehbein et al. 2004) uygulanmıştır (bk. Ek). Sanatçının Almanca sözsel sunumu, transkripsiyonda ilk satırda, sunumun Türkçe çevirisi ikinci satırda verilmiştir. Sanatçının söze eşlik eden ve söz dışı eylemleri, alt satırda tasvir edilmektedir. Yine seyircinin tepkisi, HIAT kurallarında öngörüldüğ̈̈ gibi ayrı bir satırda değil, bu alt satırda verilmiştir.

Lisa Eckhart'ın kapışma konusu bir "dünyayı kurtarma planı"dır. Bu planını üç maddeye ayırıp tek tek açıklamaktadır. Aşağıda, giriş kısmından bir kesit (1-9) verildikten sonra ikinci maddenin ele alındığı bölüm gelmektedir (24-57). Bu ikinci madde, sanatçının, "irkçıllk" sorununa getirdiği bir çözüm önerisidir. İsterse, her toplumun kendine ortak bir düşman oluşturmasının ne kadar kolay olduğunu dile getirmeye çalışan sanatçı, ırkçılığa çözüm olarak "çocukları" halk düşmanı ilan ediyor.

Lisa Eckhart sahneye siyah pantolon, siyah yelek ve ceket, beyaz bir bluzla çıkar. Kapışmada performansı ön planda tutar, seyirci ile sürekli göz temasındadır ve beden dilini iyi kullanır. Elleri ve kolları sürekli hareket halindedir. Aktarmak istediği duyguyu, jest ve mimiklerle destekler.

\begin{tabular}{|c|c|c|c|}
\hline 1 & $0[00: 00.0]$ & $1[00: 01.2]$ & $\begin{array}{l}2[00: 03.7] \\
\text { daha sessiz }\end{array}$ \\
\hline $\mathbf{L}[\mathbf{v}]$ & Am Nachmittag & - • ich mich dann trübselig doch fraag... & - Das kommt mir \\
\hline$L[\operatorname{tr}]$ & Öğleden sonra & •• kendi kendime, sıkılmış bir vaziyette, sorduğumda... & -Zaman zaman öylesine \\
\hline & $\begin{array}{l}\text { İki eli göğüs hızasında } \\
\text { konuşmaya eşlik ediyor. }\end{array}$ & Elleriyle kendini gösteriyor ve sikzlmış bir yüz ifadesine bürünüyor. & \\
\hline
\end{tabular}




\begin{tabular}{|c|c|c|c|c|}
\hline 2 & .. & $\begin{array}{l}3[00: 05.4] \\
\quad \mathrm{s} \mathrm{t} \mathrm{a} \mathrm{k} \mathrm{k} \mathrm{a} \mathrm{to}\end{array}$ & $4[00: 08.5]$ & $\begin{array}{l}5[00: 09.4] \\
\text { daha }\end{array}$ \\
\hline $\begin{array}{l}L[v] \\
L[\operatorname{tr}]\end{array}$ & $\begin{array}{l}\text { bei Zeit so in den Sinn.. } \\
\text { aklıma geliverir... }\end{array}$ & $\begin{array}{l}\text { ○ob ich Gesellschaft nützlich bin. } \\
\because \text { Acaba topluma faydalı mylm, diye. }\end{array}$ & $\begin{array}{l}\because \mathrm{Hmm} \\
\cdots \mathrm{Hmm}\end{array}$ & Meist \\
\hline $\mathbf{K}$ & & $\begin{array}{l}\text { Önce kendini gösteriyor sonra seyirciye doğru herkes } \\
\text { kastederek elleriyle yarm daire çiziyor. }\end{array}$ & i Başııı hafif yana eğiyor. & \\
\hline
\end{tabular}

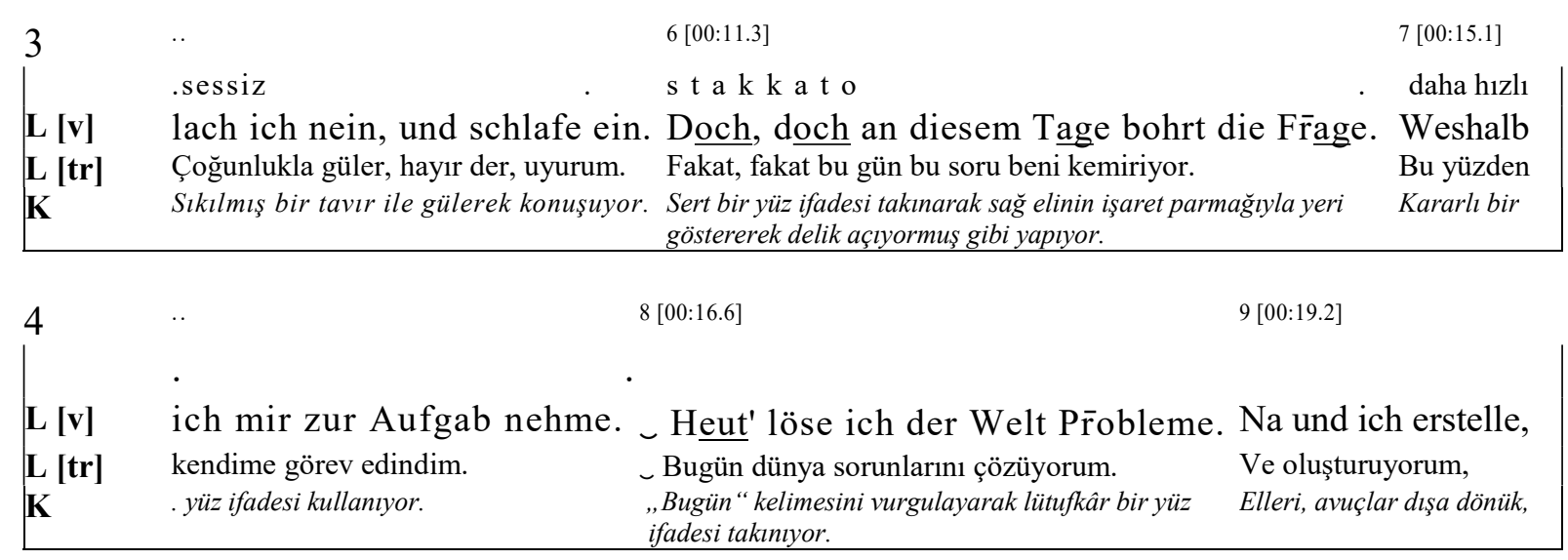

\begin{tabular}{|c|c|c|}
\hline 5 & & 10 [00:20.8] \\
\hline & & . $\mathrm{h} 1 \mathrm{z} 11$ \\
\hline $\mathbf{L}[\mathbf{v}]$ & weil ich's kann... & - einen Drei-Punkte-Plan zum Wohle für jede Männin, jeder Mann, \\
\hline$L[\operatorname{tr}]$ & çünkü yapabiliyorum.. & • bir üç maddeli plan; faydalansın diye her bay, her bayan, \\
\hline & $\begin{array}{l}\text { takindığ ukala yüz } \\
\text { ifadesine esslik ediyor. }\end{array}$ & \\
\hline
\end{tabular}

\section{6}

$11[00: 25.8]$

L [v] ehe euch noch der Teufel hole. • Und sich eines Tages zeigt, was Kapitalismus und

L [tr] șeytan sizi almadan. $\quad$ Ve bir gün gösterecek kendini, kapitalizmin ve kültürün yüzyıllardır

K Avuç içleri yere bakacakşsekilde seyirciyi „Kültür “ve „,kapitalizm “ kelimelerini yavaş, uzatarak ve vurgulayarak söylerken kastederek elleriyle havada yarım daire çiziyor.

7

L d a ha y a vas

L [v] Kultur seit Hunderten von Jahren sturr, so gefährlich haben vergeigt. $\cdots$ So habs no“

L [tr] inatla, neleri tahripkâr mahvettiğini.

K kollarını da kaldırarak havada bir sağı bir solu gösteriyor.

-. Şimdi, biraz Cebinden bir kağıt
8
$13[00: 34.2]$
$14[00: 36.8]$
$15[00: 38.5]$
L [v] bissel Zeit. $\cdots$ Drei-Punkte-Plan. Gehn wir's aaaun, okay. • Erster Pūuunkt! Hungersnot und
L [tr] zaman da var. $\cdot$ Üç maddeli plan. Başlayalım, okey. • Birinci madde! Açlık ve fakirlik. K çkartiyor. Okumaya basslyor.
9
16 [00:40.7]
$17[00: 43.2]$
L [ [v]
L $[$ tri
- Des Weltvermögens Ausgleich hinkt. Doch was hinkt, kann ja noch
• Dünya varlıklarının eşit dağılımı topallıyor,
fakat topallayan yine de yol alır, Elleriyle "dünya varllkları" kelimesine trrnak açıyor.
Elinde kağıdı tutuyor, ama serbest konuşuyor. 


\section{(...)}

24

L [v]

L [tr]

K

25

L [v]

L [tr]

K
36 [01:58.3] 37 [02:02.8]

$((4,5 s))$ Zweiter Punkt. ((1,2s)) Zweiter

İkinci madde. Alkışlar ve ıslıklar devam ediyor.

$26 \quad$.. 42 [02:09.6]

L [v] Sündenbock... • kein schwaches Herz für Hetzerpflock. Denn, wenn der Mensch kein

L [tr] •kışkırtanın kazığı için zayıf bir kalp değil... Çünkü insan, düşmanını bilmezse $\mathbf{K}$ Alaycı bir ifade ile gülerek konuşuyor.

41 [02:07.4]

- Gesellschaft braucht den - Topluma bir günah keçisi lazım..

\section{7}

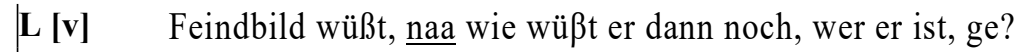

L [tr] kendinin kim olduğunu nereden bile, di mi?

K Cümlenin sonuna doğru konuşması Avusturya Almancasina kaylyor.

43 [02:15.6]

28

$\mathbf{L}[\mathbf{v}] \quad$ Herdentier.

L [tr]

K
$44[02: 17.7]$

$45[02: 19.6]$

- Und schwarze Schafe braucht die Herde. $\bullet$ Gefragt ist nur, wen

- Ve günah keçileri her sürüye lazım.

- Tek soru şu, kimi seçelim, ki "kimi" kelimesinde sesi tizleşiyor

29

46 [02:23.7]

daha yüksek sesle

L [v] wählen wir, der schwarze Schaf der Herde werde? • Da widerum sag' ich, wir

L [tr] olsun bu sürünün günah keçisi?

- İște ben de diyorum ki, biz

K

ve eliyle bir sürü içerisinden birini seçiyormuş gibi yapıyor.

\section{0}

L [v] diskriminieren die Kiiin̄der, erklären sie zu schmutzgen Minderheit unserer

L [tr] çocuklara ayrımcılık yapalım; topluluğumuzun pislik azınlığı olduklarını açıklayalım ve onları

K „,̧̧ocuklara“ kelimesini tiz bir sesle uzatıyor ve aynı anda yukarıya doğru işaret parmağı ile hedef gösterir gibi yapıyor.

31

$47[02: 31.6]$

$48[02: 32.4]$

$\mathbf{L}[\mathbf{v}]$

Gemeinschaft und deklarieren ihnen Feindschaft.

L [tr]

düşman ilan edelim.

- Na warum? In seiner

K

- Ee, neden? Ayrımcilı̆̆ın

Bir elini kaldirlyor. "en adili" derken sinsi bir yüz

32

yavaş stakkato

L [v] Ungerechtigkeit, die Diskriminierung stets begleit, wäre dies Gerechteste.

L [tr] adaletsizliğinde, ki ayrımcilığa hep eşlik eder, bu en adili olur.

K ifadesi takninyor.

Denn so ist Çünkü böylece, Sesi ve yüz 
\begin{tabular}{ll}
33 &.$\cdot$ \\
$\mathbf{L}[\mathbf{v}]$ & jeder einmal dran. \\
$\mathbf{L}[\mathbf{t r}]$ & $\begin{array}{l}\text { herkese sira gelir. } \\
\text { K }\end{array}$ \\
\hline
\end{tabular}

34

$\begin{array}{ll}\mathbf{L} \text { [v] } & \begin{array}{l}\mathrm{h} 1 \mathrm{z} 11 \\ \text { Natiooon und welches Kindlein stört das schon. } \\ \mathbf{L} \text { [tr] }\end{array} \\ \text { rahatsiz ederki bu. }\end{array}$

K „ulus “ kelimesini tiz bir şekilde uzattıktan sonra sinsice gülüyor.
$51[02: 46.5]$

daha hizlı

Im Mittelpunkt, ob gut, ob schlecht, ist İyi ya da kötü, ilgi odağı olmak Ses tonunda alaycı bir hava ile konuşuyor. "iyi" "kötü"

\begin{tabular}{|c|c|c|c|c|}
\hline & & $52[02: 50.1]$ & 53 [02:50.9] & $54[02: 52.8]$ \\
\hline & & & h 1 z 11 & yüksek sesle \\
\hline & jedem Kin & - Zude $\overline{\mathrm{m}}$ & $\bullet \bullet$ ergibt & $\bullet$ Denn \\
\hline & $\begin{array}{l}\text { her çocuğa gönülden uyar. } \\
\text { derken ellerini să̆ } \text { ve sola acivor }\end{array}$ & $\begin{array}{l}\text { • Ayrica ... } \\
\text { Ciddivete bürü̈n }\end{array}$ & $\begin{array}{l}\cdots \text { gayet mantıklı. } \\
\text { rekrar }\end{array}$ & $\begin{array}{l}\text {-・ İyice bir } \\
\text { Sinirlive }\end{array}$ \\
\hline
\end{tabular}

\begin{tabular}{|c|c|c|}
\hline 36 & .. & $55[02: 55.4]$ \\
\hline & & yüksek sesle; daha yavaş \\
\hline$[\mathbf{v}]$ & schauts' nur mal genauer hin! & - - Entartet sind sie allesamt; mit kleinen Händen, \\
\hline & bakın! & • •Hepsinin soyları bozulmuş; küçük eller, küçük ayaklar. \\
\hline & dişlerini sıkarak konuşuyor. & "soyları bozulmuş" kelimesini „r“yi fazlaca vurgulayarak söylüyor. Kızgınlı̆̆ın \\
\hline
\end{tabular}

37

L [v] kleinen Füßen.

L [tr]

K

56 [02:59.9]

yüksek sesle; stakkato

Als Säugling sind sie kaum im Stand Bebekmiş, adamakıllı Alman tarzı selam Ciddi ve yüksek bir ses tonuyla konuşuyor. "ordentlich"

$38 \quad . . \quad 57[03: 03.7] \quad 58[03: 05.4] \quad 59[03: 05.7] \quad 60[03: 08.6] 61[03: 08.9]$

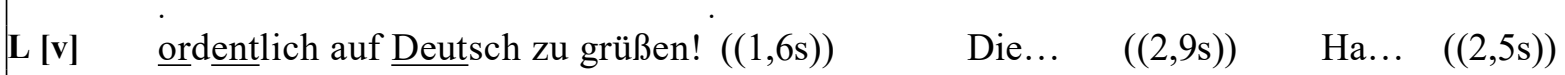

L [tr] bile veremiyorlar!

K kelimesindeki „r"yi vurguluyor."Alman" Seyirci gecikmeli tepki kelimesini yüksek sesle ve sertçe söylüyor ve veriyor ve gülüyor. askerlerin selamlama hareketini yapıyor Alklş geç geliyor.

$\begin{array}{ll}\text { Sakinleşmeye } & \text { Seyirci } \\ \text { çalışır bir eda } & \text { alkışlamaya } \\ \text { ile kendini } i & \text { devam } \\ \text { toplamaya çallşlyor } & \text { ediyor. }\end{array}$

\begin{tabular}{|c|c|c|c|}
\hline 39 & $62[03: 11.4]$ & $63[03: 14.0]$ & $64[03: 16.0]$ \\
\hline & yüksek sesle & yüksek sesle; stakkato & yüksek \\
\hline $\mathrm{L}[\mathbf{v}]$ & Die Sprache $((0,5 s))$ wollen sie nicht verstehn. & Mit einem Jahr zu faul zum Gehn. & - Neun \\
\hline$[\mathbf{t r}]$ & Dili anlamak istemiyorlar. & Bir yaşına girmiş yürümeye üşeniyorlar. & •-Dokuz ay \\
\hline & Klzgın ve sert bir ses tonuyla her kelimenin üstüne basa bas & sa konuşuyor. & Karşısılndakini \\
\hline
\end{tabular}

40

sesle . yüksek sesle; stakkato $65[03: 21.0]$

L [v] Monate $((0,5 \mathrm{~s}))$ haben sie's gratis fein in Mutters Asylantenheim, ja. $\bullet \underline{\text { Da }}$, da leben sie woohl

L [tr] onlara herşey bedava, annenin sı̆̆ınma evinde, evet.

K küçük görme tavriyla yüzünü ekşiterek kizmaya devam ediyor.

- Orda, orda gayet rahat yaşıyorlar Küçük görme ve suçlayıcı tavrını 


\begin{tabular}{|c|c|c|c|}
\hline & .. & $66[03: 26.3]$ & $67[03: 27.9]$ \\
\hline & & daha sessiz; daha hızlı & hizli \\
\hline$[\mathbf{v}]$ & voll dekadent an freessen da Mutter ihr Plaseenta. & - Was, was heißt da noch.. & - das \\
\hline $\begin{array}{l}\mathbf{L}[\mathbf{t r}] \\
\mathbf{K}\end{array}$ & $\begin{array}{l}\text { ve annenin plasentasını yok edercesine zıkkımlanıyorlar. } \\
\text { kelimeleri yayarak dalga geçme ile birleştiriyor. }\end{array}$ & - Ne, ne demek hala... & - tatli \\
\hline
\end{tabular}

\begin{tabular}{|c|c|c|c|}
\hline 42 & .. & 68 [03:28.9] & 69 [03:30.8] \\
\hline & & . daha yavaş; daha yi & \\
\hline$[\operatorname{tr}]$ & yavrucuk? & $\begin{array}{l}\text { Beleşçi bunlar ve serseri. } \\
\text { Kizgın bir yüz ifadesiyle devam ediyor. }\end{array}$ & - " Bunlar entegre olmak istemiyorlar; \\
\hline
\end{tabular}

70 [03:35.3]

yavaş; daha sessiz

L [v] integrieren, sind asozial, nur unter sich. • U Und ihre fremdartigen Manieren sind

L [tr] asosyaller; sürekli bir arada.

K vurguluyor. Sanki seyirciye bir sir verir gibi yapiyor.

- Hele garip adapları, gelişmişlik açısından oldukça Şüphe içeren bakışlarla gizli bir şey söylüyormuşcasına

\begin{tabular}{|c|c|c|c|}
\hline 44 & .. & $71[03: 39.8]$ & $72[03: 42.4]$ \\
\hline & & . daha hizli & daha yavaş \\
\hline$[\mathbf{v}]$ & kulturell sehr wunderlich. & - - Wie sie sich aus dem Glauben schwindeln. & - Tragen kein \\
\hline$[\mathbf{t r}]$ & tuhaf. & - Nasil da dinden kaytarıyorlar. & • Baş örtüsü \\
\hline & konuşuyor. & & Kafasint işaret ediyor \\
\hline
\end{tabular}

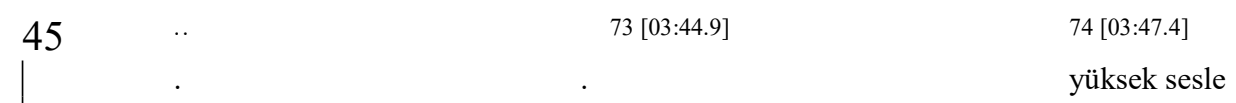

L [v] Kopftuch aber Wiiindeln. Beten nicht $((0,5))$ zu Gott, $\underline{\text { Allah. Ihr Heidengott heißt Frau }}$

L [tr] takmıorlar, ama bez kullanıyorlar. Dua etmiyorlar Tanrıya, Allah’a. Kafir tanrılarının adı „Anne“!

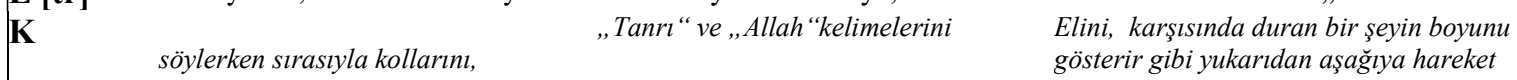
yukarııı işaret ederek uzatiyor. ettiriyor. Ses tonu kızgın. Sakinleşmeye

\begin{tabular}{|c|c|c|c|c|}
\hline 46 & .. & $75[03: 50.3]$ & $76[03: 52.0]$ & $77[03: 54.7]$ \\
\hline & & & yavaş & daha yavaş; daha sessiz \\
\hline $\mathbf{L}[\mathbf{v}]$ & Mamaa! und... & $((1,7 \mathrm{~s}))$ & Schaut se euch an $((1 \mathrm{~s}))$ in Bangladesch. & - - Wer flickt denn das \\
\hline L [tr] & $\overline{\text { ve.... }}$ & & Bir bakın, Bagladeş'tekilere. & - Kim dikiyor o kıyafetleri öyle \\
\hline & çalışıyor. & Seyirci kahkahalart. & $\begin{array}{l}\text { Kafa tutar bir beden dili ile gözlerini kısarak } \\
\text { konuşuyor. }\end{array}$ & Hoşnutluk ifade eden bir sesle \\
\hline
\end{tabular}

$\begin{array}{lll}47 & . & 78[03: 59.7]\end{array}$

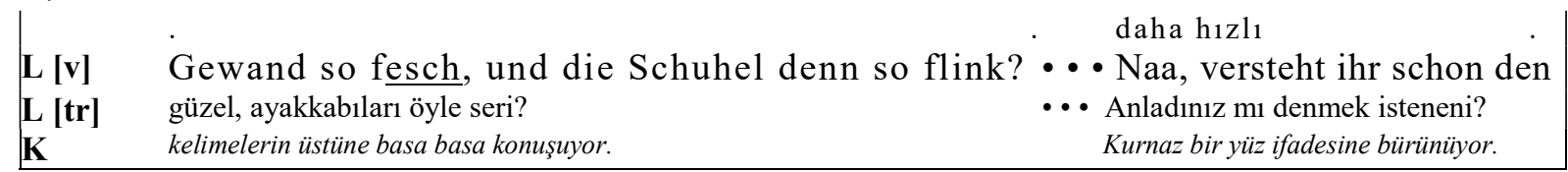

\begin{tabular}{|c|c|c|}
\hline 48 & $79[04: 01.8] 80[04: 03.3]$ & $81[04: 04.1]$ \\
\hline & yavaş & yüksek sesle \\
\hline$[\mathbf{v}]$ & W ink? $((1,4 \mathrm{~s}))$ Die Kiinder... & - • nehmen uns die Arbeitsplätze weg! \\
\hline$[\mathbf{t r}]$ & Bu çocuklar... & • • iş yerlerimizi çalıyorlar! \\
\hline & & Beklenmedik bir şekilde kizgınlıkla bağırıyor. \\
\hline
\end{tabular}




\begin{tabular}{|c|c|c|}
\hline 49 & $82[04: 07.0]$ & $83[04: 17.3]$ \\
\hline $\begin{array}{l}\mathrm{L}[\mathbf{v}] \\
\mathrm{L}[\mathbf{t r}]\end{array}$ & $((10,3 s))$ & $\begin{array}{l}\text { yüks ek se sle } \\
\text { Drum/ drum Zeit wirds, dass man sie versteckt... Den } \\
\text { Bu/ bu nedenle artık onları saklamanın zamanı geldi. }\end{array}$ \\
\hline $\mathbf{K}$ & Seyirciden kahkalar ve alkışlar yükseliyor. & Sakinleşmeye çallşıyor. Sesi titriyor. \\
\hline
\end{tabular}

\begin{tabular}{|c|c|c|}
\hline 50 & . & $85[04: 24.1]$ \\
\hline & yavaş; daha sessiz & yüksek sesle; stakkato \\
\hline $\mathbf{L}[\mathbf{v}]$ & Kindertages-lager-stätten, wo sie es denn eh viel besser hätten. & - Die Einrichtungen wären \\
\hline L [tr] & Günlük çocuk bakım kamplarında. Çok daha iyi olurlar orada. & - Yerleri zaten hâlihazırda. \\
\hline & 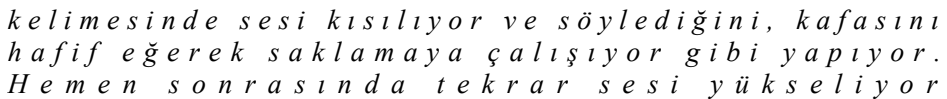 & \\
\hline
\end{tabular}

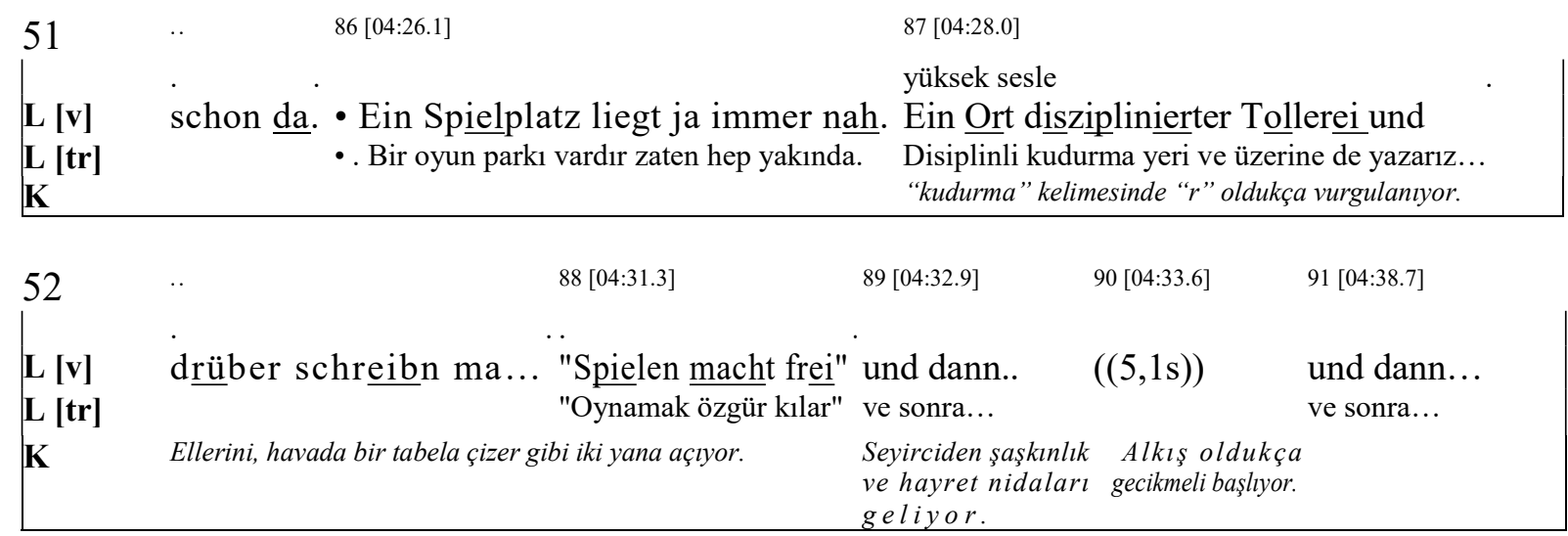

$53 \quad 92[04: 39.4]$

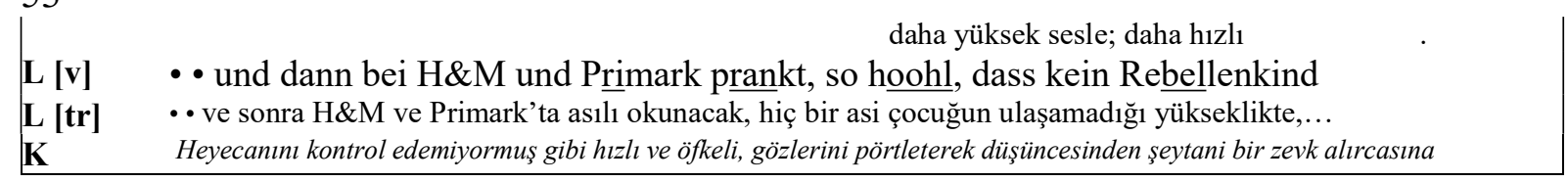

\begin{tabular}{|c|c|c|}
\hline 4 & & 9] \\
\hline & & daha y \\
\hline & herangelangt.. & Das wird die Kaufeslust wohl mindern, in grooßer Schrift: „Kauft nicht bei \\
\hline r] & konuşmaya devam & $\begin{array}{l}\text { Bu alış veriş sevdasını alacak; büyük harflerle, „Çocuklardan alış veriş yapmayın!“‘. } \\
\text { ediyor. }\end{array}$ \\
\hline
\end{tabular}

$\begin{array}{llll}55 & . & 94[04: 49.8] & 95[04: 50.3]\end{array}$

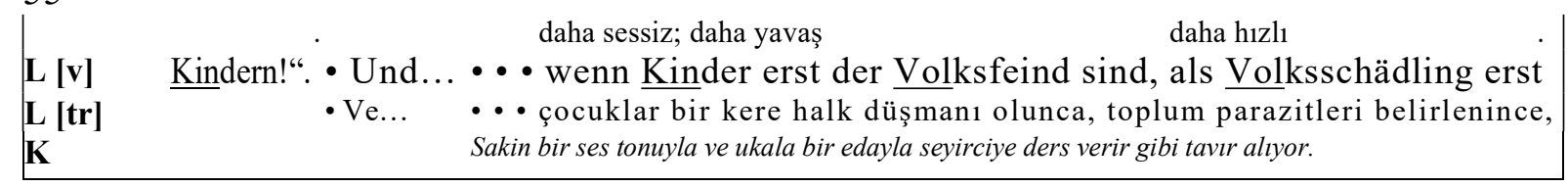

\begin{tabular}{|c|c|c|}
\hline 56 & .. & 96 [04:56.5] \\
\hline $\begin{array}{l}\mathbf{L}[\mathbf{v}] \\
\mathbf{L}[\mathbf{t r}] \\
\mathbf{K}\end{array}$ & $\begin{array}{l}\text { mal bestimmt, die weiße Unschuld fort sodann... } \\
\text { o beyaz saflık da gidince... }\end{array}$ & $\begin{array}{l}\text { • Dann rüührt sie auch niemand } \\
\text { • O zaman kimse bir daha yaklaşmaz onlara. } \\
\text { "rührt" (dokunmak) kelimesindeki ,,r"yi fazlaca } \\
\text { vurguluyor ve sinsice gülümsüyor. }\end{array}$ \\
\hline
\end{tabular}




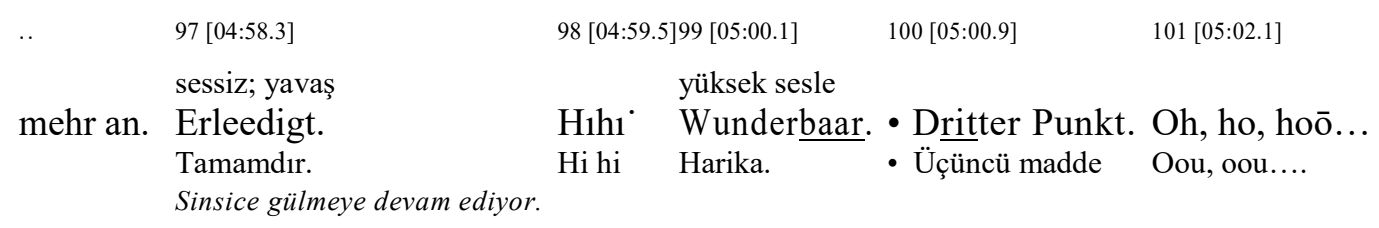

Eckhart'ın sunumunda hız ve ritim, hece vurguları ile elde edilmiştir. Hece vurguları, antik bir mısra ölçüsü olan yambus (Yun. ïambos; Lat. iambus) ile düzenlenmiştir. Yer yer Alman Dili'nin özellikleri doğrultusunda değişiklik gösterseler de Hellen ve Latin şiir ölçüleri Alman Edebiyatı'nda sıkça kullanılır. Yambus, arka arkaya gelen iki hecenin ilkinin zayıf vurgulu ( - ), ikincisinin kuvvetli vurgulu ( ' ) olmasindan elde edilir:

We ${ }^{-}$Go'tt wi ${ }^{-} 11$ re'chte $^{-}$Gu'nst e rwei'se ${ }^{-} n$

(Eichendorff (1995), Der frohe Wandersmann şiirinin ilk misrası - Tr. çev. Kime tanrı iyilik etmek isterse)

Örnekte, kuvvetli vurgu ile vurgulanan dört hece, mıranın ritmini belirler. Bu misra, dört çekmeli bir yambus'tur. Misranın sonu zayıf ya da kuvvetli hece vurgusu ile bitebilir. Eckhart'in ölçü olarak yambus'u seçme sebebi tesadüf değildir, çünkü yambus ölçüsü genellikle şaka, şaklabanlık, dalga geçme ve alay etme gibi durumlarda kullanılır. Ölçünün ismi de, Hellen mitolojisinde şakalarıyla Demeter'i güldürmeye ve neşelendirmeye çalışan akıllı hizmetçisi Iambe'den gelmektedir. Eckhart da, 'dünyayı kurtarma' planını anlatırken ukala ve alaycı bir tavır takınmaktadır. Seçtiği sözler ve takındığı tavır ayrıca Goethe'nin Faust eserindeki Mephisto'yu (şeytanı) çağrıştırır. Goethe de eserinde Mephisto'nun mısralarını yambus ölçüsü ile vermiştir. Eckhart'ın sesinin ara ara tizleşmesi (bk. kesit 28, 30, 34) ve sunumunun bazı noktalarında (31, $34,56,57)$ sinsice gülmesi de bu sebepledir. Eckhart'ın sunumundan örnek yambus ölçüsü şu şekildedir (25-27):

$\mathrm{Ge}^{-} \mathrm{se}^{\prime}$ llscha ${ }^{-} \mathrm{ft}$ brau'cht de ${ }^{-} \mathrm{n}$ Sü'nde ${ }^{-}$nbo'ck,

$\mathrm{Kei}^{-} \mathrm{n}$ schwa'che ${ }^{-} \mathrm{s}$ He'rz fü ${ }^{-} \mathrm{r} \mathrm{He}^{\prime} \mathrm{tze}^{-}$rpflo'ck.

$\mathrm{De}^{-} \mathrm{nn}$, we'nn de $\mathrm{r}$ Me'nsch kei ${ }^{-} \mathrm{n}$ Fei'ndbi ${ }^{-} \mathrm{ld}$ wü' $\beta \mathrm{t}$,

$N a$, wie ${ }^{-}$wü' $\beta \mathrm{t} \mathrm{e}^{-} \mathrm{r}$ da'nn no ${ }^{-} \mathrm{ch}$, we'r $\mathrm{e}^{-} \mathrm{r}$ i'st, ge?

Son mısradaki Na (T. eh işte; yani) ve ge (T. değil mi), Almancada konuşma diline has ünlem sesleridir. Burada vurgusuz olarak şiire eklenmişlerdir. Kapışma edebiyatının metinlerarasılık özelliğine uygun olarak konuşma ve şiir dili, iç içedir. Vurgulu hecelerin eşit aralıklarla dizilişi, şiire ritmini verir.

Kapışma edebiyatının, ses oyunlarıyla seyircide uyandırmak istediği çağrışımı, oldukça başarılı bir şekilde elde ettiği, kesit $36,37,50,51,52,54,55$ ve 56'da görülmektedir. Burada Mephisto'dan ziyade Hitler karşımıza çıkmaktadır. Hitler' in konuşmalarında /r/ seslerini vurguladığı bilinmektedir. Eckhart, /r/ seslerini özellikle vurgularken $(36,37,51)$ ayn1 anda, Hitler'in söylemlerinde sıkça geçen bazı kavramları da dile getirir. Kesit 36'da "entartet" (Tr. soyu bozuk), 37'de "Deutsch" (Tr. Alman), 50'de "lager" (Tr. kamp), 55'de "Volksfeind; Volksschädling" (Tr. halk düşmani; toplum paraziti) kavramları, nasyonal sosyalistleri çağrıştırmaktadır. Ses oyunları ve kavramlar birleşince seyirci gösterileni anlamakta zorlanmıyor. Göndermeler, beden dili ile de destekleniyor. Kesit 50'de, "Kindertageslagerstätten" (Tr. çocuk bakım kampları) kelimesinin içindeki "lager" (Tr. kamp) toplama kamplarına gönderme yaptığ1 için Eckhart, tam "lager" derken başını hafif yana eğerek seyirciyle göz temasını kesiyor ve 
söylediğini herkesin duymasını istemiyormuş gibi yapıyor. Sesini de burada oldukça kısıyor.

$\mathrm{Bu}$ örnekte, Hitler söylemlerinin dile getirildiği kısımlarda, şair kapışmasının diğer bir özelliği olan, performansı seyirci ile karşılıklı geliştirme ve oluşturma da çok net ortaya çıkıyor. Eckhart, /r/ sesini vurgulayarak çocuklar için "adam akıllı Alman tarzı selam bile veremiyorlar" dediği ve askervâri bir selam verdiği anda (38), birden Hitler'i karşısında bulan seyirci, önce nasıl tepki vereceğini şaşırıyor. Performansı alkışlamak istiyor, ama Hitler söylemini desteklemek istemiyor. Bu nedenle, önce tek tük alkış ve gülme sesleri geliyor ve sonrasında, seyirci, yaşadığı mahcubiyet ve şaşırmayı üstünden atınca, gecikmeli de olsa alkışlıyor. Eckhart ise, seyircinin hareketli olduğu bu gecikmeli tepki süresince beden dili ile kendini toplamaya çalışırmışçasına hareketler yaparak seyircinin kendisini doğru anladığının sinyallerini veriyor. Aynı tepkiyi kesit 52'de de görüyoruz. Burada çağrışım, daha büyük mahcubiyete ve tepkiye yol açıyor. Seyirci, sekiz saniyeye yakın bir süre alkışı geciktiriyor. Hatta bazı seyirciler gülerken elleri ile ağzını kapatıyor; nasıl tepki vereceklerine şaşırıyorlar. Kesit 52'de, Yahudilerin bulunduğu ve çalıştırıldıkları toplama kamplarında asılı olan bir tabelaya gönderme yapıyor Eckhart. Seyircilerin çoğunun bildiği bu yazıda "Arbeit macht frei!" (Tr. Çalışmak özgür kılar!) ifadesi bulunmaktaydı. Bu yazıya analoji kuran Eckhart, halk düşmanı ilan ettiği çocuklar için "Spielen macht frei!" (Tr. Oynamak özgür kılar!) ifadesini kullanmaktadır.

Mısra sonu uyakları (genellikle aa, bb) ile birlikte, sanatçı, mısra içinde de aliterasyon ve asonansa bolca yer vermiştir. Aliterasyon, arka arkaya gelen kelimelerin başındaki ünsüzlerin; asonans ise, ünlülerin tekrar etmesidir. Özellikle bu iki deyiş sanatı, söylenene ritim kazandırma yanı sıra bir tür melodi de oluşturur.

Aliterasyon için örnekler:

5 Einen Drei-Punkte-Plan, Zum Wohle für jede Männin, jeder ㅆann

26-27 Denn, wenn der Mensch kein Feindbild wüßßt, $\mathrm{Na}$, wie wüßßt er dann noch, wer er ist, ge?

28-29 Gefragt ist nur, wen_wählen wir, der schwarze Schaf der Herde werde?

40-41 $\underline{\mathrm{Da}}$, da leben sie wohl voll dekadent an freessen da Mutter ihr Plasenta

53 und dann bei H\&M und Primark prankt

54-55 Das wird die Kaufeslust wohl mindern, in großer Schrift: „Kauft nicht bei inindern!“

Asonans için örnekler:

28 Und schwarze Schafe braucht die Herde

28-29 der schwarze Schaf der Herde werdẹ?

40-41 Dạ, da leben sie wohl voll dekâdent an freessen da Mutter ihr Plassenta

51 Ein Spielplatz liegt jạ immer nah

55-57 Die weiße Unschuld fort sódann... dannn rührt sie auch niemand mehr an 
Özellikle aliterasyon sanatı, Almancada oldukça verimli bir uygulamadır ve sözsel iletiye melodi kazandırır. Aliterasyon, eski Germen kültüründe sözsel aktarılan şiirlerin ana özelliklerinden biridir. Şiire kattığı ritim ve melodiden dolayı, Germen şiirlerine genellikle Lied (Tr. şarkı) denir. Aliterasyon ve asonans, yambus ölçüsünün kuvvetli vurgularının da bulunduğu hecelere denk geldiğinde, ritim daha belirgin hissedilir.

Kesit 40 ve 41 'deki "D $\underline{a}$, da leben sie wohl voll dekadent an fressen da Mutter ihr Plasentá" içindeki /a/ ünlüsünün tekrarları ile sağlanan asonansı çoğaltmak için Eckhart, Almanca'daki und (Tr. ve) yerine, Avusturya ağZı konuşma dilindeki karşılı̆̆ 1 an'ı kullanmıştır. Yine bu kesitte, aliterasyon ve asonansların birikmesi, sözsel aktarımın burada hızlanması, anlamsal içeriği desteklemektedir. Kızgınlığın belirtildiği ve Eckhart'ın burada kendini kaybedermişcesine kızmaya başlaması, hız ve ritimle tamamlanmaktadır. Öyle ki, bu kısmın sonunda (46) Eckhart, yüksek sesle derin nefes alıyormuş gibi yaparak sakinleşmeye çalıştığ 1 izlenimini söz dışı hareketlerle de destekleyerek vermektedir.

\section{Sonuç}

Şair kapışması, sıradan bir şiir dinletisinden çok farklı olarak sözel ve teatral bir yetenek gerektirir. Tür olarak, edebiyata dâhil edilse de, sahne performansı çogu kez metnin önüne geçer. Almanya'da popülerliği günden güne artan ve gençleri tekrar şiirle buluşturan bu yeni akımın tarihi gelişimi ve özellikleri bu çalışmada ele alınmıştır. "Şair kapışması" ve "kapışma edebiyatı" kavramları açıklanmıştır. Hiphop kültürü ve sözsel edebiyat akımları ile bağlantısı irdelenmiştir. Gençlerin ilgisini çekmesi ise, güncel konulara değiniyor olması, konuşma diline de ver vermesi, jürinin seyirciler arasından seçilmiş olması ve yarışma formatında gerçekleşmesi ile açıklanmıştır. İncelenen örnekte, edebiyata yatkınlığın yanı sıra sesi ve beden dilini etkili kullanmanın, ne denli performansı etkilediği görülmüştür. Yine örnekte, sahnedeki sanatçı ile seyirci arasındaki performans boyunca devam eden etkileşimin, nihayetinde asıl ürünü oluşturduğu izlenmiştir. Kapışan şairlerden, merak uyandırma, sesini ve beden dilini etkili kullanma, yorum yapabilme, şaşırtabilme ve metni duygu ile yükleyebilme beklenir. Böylece edebiyat, hem deneysel hem de canlı yaşanmış olur.

\section{Kullanılan Transkripsiyon İșaretleri}

[v] : sözsel (İng. verbal) dil satır

[tr] : çeviri satırı (Türkçe)

$\mathrm{K} \quad$ : söz dişı eylemlerin yorum satırı

sessiz : ilk satırın üstünde; fark edilir hız, ses düzeyi değişimini belirtir (stakkato: ifadelerin kısa ve kesik kesik gelmesi)

- $\quad$ : çok kısa duraksama

- $\quad$ : kisa duraksama (en fazla $1 / 2$ saniye)

... : uzun duraksama

$((4,5 \mathrm{~s}))$ : duraksama süresi 1 saniyenin üzerinde ise süre belirtilir

- $\quad$ : iki ifade arası çok hızlı geçiş

I : kelimenin ya da ifadenin yarıda kesilmesi, düzeltilmesi

jeder : vurgulu hece ya da kelime (bağlama kıyasla)

Frage : vurgulu ünsüz

$\hat{\mathrm{m}} \quad$ : çıkan ve düşen tonlama

fraaag : ünlülerde uzatma (uzatmaya göre ünlü 2 ya da 3 kere yazılır)

(...) : transkribe edilmeyen, atlanılan kısım 


\section{KAYNAKÇA}

Algarín M. \& Holman B. (1994). Aloud: Voices from the Nuyorican Poets Cafe. New York 1994.

Anders P. (2007). Slam Poetry: Inszenierte Bühnen-Poesie. Kaynak: http://www.slam2007.de/slam/ docs/SlamPoetry.pdf. Erişim Tarihi 01.10.2016.

Beatty P. \& Marrs S. (1994²). Slam! Poetry: Heftige Dichtung aus Amerika. Berlin 1994.

Eichendorff J. v. (1995). Werke in einem Band. Münih 1995.

Hager S. (2006). Literarische Texte rezipieren, produzieren und präsentieren. Poetry Slam im integrativen Deutschunterricht der Realschule. Yayımlanmamış Yüksek Lisans Tezi. Pädagogische Hochschule, Ludwigsburg 2006.

Meyers Kleines Lexikon: Literatur. (1986). Mannheim, Viyana, Zürih 1986.

Nikolai V., Orjuela A. \& Schrenk N. (2009). "Drei Dimensionen der Slam Poetry: Performance, Ethos und Widerstand". Ars Semeiotica 32/1-2 (2009) 137-150.

Preckwitz B. (1997). Slam Poetry. Nachhut der Moderne: Eine literarische Bewegung als AntiAvantgarde. Berlin 1997.

Rehbein J., Schmidt T., Meyer B., Watzke F. \& Herkenrath A. (2004). Handbuch für das computergestützte Transkribieren nach HIAT: Version 1.0. Arbeiten zur Mehrsprachigkeit Folge B: Vol. 56. Hamburg 2004.

Riedel M. Slam Poetry - interkulturell: Zur Didaktik mündlich vorgetragener deutschsprachiger Texte. Kaynak:http://www.germanistik.uni-muenchen.de/personal/didaktik/mitarbeiter/riedel/riedel_ slampoetry.pdf. Erişim Tarihi 03.03.2016.

Riha K. \& Wende W. (1992). Dada Zürich: Texte, Manifeste, Dokumente. Stuttgart 1992.

SLAM 2015: Die deutschsprachigen Poetry Slam-Meisterschaften in Augsburg. (07 Kasım 2015) [Televizyon Yayın1]. Einsfestival-ARD. Kaynak: http://www.ardmediathek.de/tv/SLAM-2015-diedeutschsprachigen-Poetry/Das-Slam-Finale-in-voller-L\%C3\%A4nger/BR de/Video?bcastId=31519492\&documentId=31585416. Erişim Tarihi 02.10.2016.

Smith M. K. \& Kraynak J. (2004). The Complete Idiot's Guide to Slam Poetry. Indianapolis 2004.

Urbach T. (Yönetmen). (05 Kasım 2015). Slam Poetry: Helden der Dichtung [Televizyon Yayını]. Bayerischer Rundfunk.

Webster's Seventh New Collegiate Dictionary. (1963). Springfield 1963.

Wirag L. (2014). "Die Geburt des Poetry Slams aus dem Geist des Theaters". KulturPoetik 14/2 (2014) 269-281. 